\title{
Lasmiditan is an effective acute treatment for migraine
}

\author{
A phase 3 randomized study
}

Bernice Kuca, BA, MS, Stephen D. Silberstein, MD, Linda Wietecha, BSN, MS, Paul H. Berg, MS, Gregory Dozier, MPH, and Richard B. Lipton, MD, on behalf of the COL MIG-301 Study Group

Neurology ${ }^{\circledR}$ 2018;91:e2222-e2232. doi:10.1212/WNL.0000000000006641

\section{Abstract}

\section{Objective}

To assess the efficacy and safety of lasmiditan in the acute treatment of migraine.

\section{Methods}

Adult patients with migraine were randomized (1:1:1) to a double-blind dose of oral lasmiditan $200 \mathrm{mg}$, lasmiditan $100 \mathrm{mg}$, or placebo and were asked to treat their next migraine attack within 4 hours of onset. Over 48 hours after dosing, patients used an electronic diary to record headache pain and the presence of nausea, phonophobia, and photophobia, one of which was designated their most bothersome symptom (MBS).

\section{Results}

Of the 1,856 patients who treated an attack, $77.9 \%$ had $\geq 1$ cardiovascular risk factors in addition to migraine. Compared with placebo, more patients dosed with lasmiditan $200 \mathrm{mg}$ were free of headache pain at 2 hours after dosing (32.2\% vs $15.3 \%$; odds ratio [OR] 2.6, 95\% confidence interval [CI] 2.0-3.6, $p<0.001)$, similar to those dosed with lasmiditan $100 \mathrm{mg}$ (28.2\%; OR 2.2, 95\% CI 1.6-3.0, $p<0.001)$. Furthermore, compared with those dosed with placebo, more patients dosed with lasmiditan $200 \mathrm{mg}$ (40.7\% vs 29.5\%; OR 1.6, 95\% CI 1.3-2.1, $p<0.001)$ and lasmiditan $100 \mathrm{mg}$ (40.9\%; OR 1.7, 95\% CI, 1.3-2.2, $p<0.001)$ were free of their MBS at 2 hours after dosing. Adverse events were mostly mild or moderate in intensity.

\section{Conclusions}

Lasmiditan dosed at 200 and $100 \mathrm{mg}$ was efficacious and well tolerated in the treatment of acute migraine among patients with a high level of cardiovascular risk factors.

\section{ClinicalTrials.gov identifier \\ NCT02439320.}

\section{Classification of evidence}

This study provides Class I evidence that for adult patients with migraine, lasmiditan increases the proportion of subjects who are headache pain free at 2 hours after treating a migraine attack.

\author{
Correspondence \\ Ms. Wietecha \\ wietecha_linda_a@lilly.com
}

\section{RELATED ARTICLE}

\section{Article}

Galcanezumab in chronic migraine: The randomized, double-blind, placebocontrolled REGAIN study Page 1082

\section{MORE ONLINE}

\section{$\rightarrow$ Class of Evidence}

Criteria for rating therapeutic and diagnostic studies

NPub.org/coe 


\section{Glossary}

FDA = Food and Drug Administration; ITT = intent-to-treat; MBS = most bothersome symptom; MIDAS = Migraine Disability Assessment; mITT = modified intent-to-treat; TEAE $=$ treatment-emergent adverse event.

Migraine is ranked by the World Health Organization as the world's second leading cause of disability. ${ }^{1}$ Triptans, a class of serotonin $5-\mathrm{HT}_{1 \mathrm{~B} / 1 \mathrm{D}}$ receptor agonists (some of which also act at 5 - $\mathrm{HT}_{1 \mathrm{~F}}$ receptors), are the most widely used specific antimigraine therapies. ${ }^{2}$ Triptans cause vasoconstriction by activation of $5-\mathrm{HT}_{1 \mathrm{~B}}$ receptors, ${ }^{3-5}$ conferring a small risk of serious cardiovascular adverse events. ${ }^{6}$ Triptans are contraindicated in patients with certain cardiovascular conditions and events such as vascular disease, hemiplegic migraine, uncontrolled hypertension, and stroke, and product labels contain warnings for patients with cardiovascular risk factors. ${ }^{7,8}$ Because cardiovascular conditions, events, and procedures are common in migraine ${ }^{9-11}$ and because $\approx 30 \%$ to $40 \%$ of patients with migraine do not respond to triptans, ${ }^{12}$ there is a need for new acute migraine treatments.

Lasmiditan is a high-affinity, highly selective $5-\mathrm{HT}_{1 \mathrm{~F}}$ receptor agonist that acts on the trigeminal system without causing vasoconstriction because of its low affinity for $5-\mathrm{HT}_{1 \mathrm{~B}}$ receptors. ${ }^{13}$ Lasmiditan is being developed as an acute therapy for migraine to address significant unmet needs in patients with cardiovascular risk factors, those with stable cardiovascular disease, or patients who respond poorly to their current treatment. In a phase $2 \mathrm{~B}$ study, oral lasmiditan was safe and effective in the acute treatment of migraine. ${ }^{14}$ In this first phase 3 , prospective, randomized, double-blind, placebo-controlled study to assess the efficacy and safety of lasmiditan $(200$ and $100 \mathrm{mg}$ ) in the acute treatment of migraine, patients with cardiovascular risk factors were intentionally enrolled. This phase 3 pivotal trial, with a prespecified modified intent-to-treat (mITT) analysis population, was conducted under Special Protocol Assessment with the US Food and Drug Administration (FDA). ${ }^{15}$

\section{Methods}

\section{Primary research question}

This study in patients with migraine headache pain was conducted to evaluate the efficacy of lasmiditan 200 and $100 \mathrm{mg}$ vs placebo as measured by the proportion of patients who became headache pain free (primary endpoint $200 \mathrm{mg}$, key secondary endpoint $100 \mathrm{mg}$ ) and most bothersome symptom (MBS) free (key secondary endpoint) at 2 hours. This study provides Class I evidence that for adult patients with migraine, lasmiditan increases the proportion of subjects who are headache pain free at 2 hours after treating a migraine attack.

\section{Standard protocol approvals, registrations, and patient consents}

The study was conducted in accordance with the International Conference on Harmonisation Good Clinical Practice guideline and local regulatory requirements. The study protocol was approved by an independent ethics committee or institutional review board at each study site. All patients provided written informed consent before the start of the study. The study was registered at ClinicalTrials.gov (identifier: NCT02439320).

\section{Study population}

Key patient inclusion criteria were as follows: male or female; $\geq 18$ years of age; a diagnosis of migraine with or without aura fulfilling the International Headache Society diagnostic criteria 1.1 or 1.2.1 ${ }^{16}$; a history of disabling migraine for at least 1 year; a Migraine Disability Assessment (MIDAS) $)^{17,18}$ total score of $\geq 11$; migraine onset before 50 years of age; and a history of 3 to 8 migraine attacks per month ( $<15$ headache days per month).

Key exclusion criteria were a history within the past 12 months of chronic migraine or other forms of primary or secondary chronic headache disease (e.g., hemicranias continua) or medication-overuse headache with a headache frequency of $>15$ headache days per month; initiation of or change in migraine preventive medication within 3 months before screening; and known coronary artery disease, clinically significant arrhythmia, or uncontrolled hypertension. Patients at increased risk for seizures were also excluded.

\section{Study design}

This randomized, double-blind, placebo-controlled study was initiated on April 27, 2015, and completed on August 12, 2016. Patients were enrolled by study site personnel at 99 centers in the United States.

At the screening visit (visit 1), patient eligibility was assessed, and patients were randomized (1:1:1) to a first dose of lasmiditan $200 \mathrm{mg}$, lasmiditan $100 \mathrm{mg}$, or placebo. Patients were also randomly allocated to a second dose of lasmiditan or placebo for rescue or recurrence of migraine (patients in the lasmiditan $200 \mathrm{mg}$ group were randomized [2:1] to lasmiditan $200 \mathrm{mg}$ or placebo as the second dose; patients in the lasmiditan $100 \mathrm{mg}$ group were randomized [2:1] to lasmiditan $100 \mathrm{mg}$ or placebo as the second dose; and all patients in the placebo group received placebo as the second dose). Patients were instructed not to treat an attack until their eligibility had been confirmed by phone (within 7 days) after completion of all screening evaluations, including laboratory tests.

Patients were randomized through a central randomization process by interactive response technology. Patients were stratified (yes or no) for use of concomitant migraine preventive medication. A randomization number and study drug card number were assigned to each patient. Study drugs (lasmiditan and matching placebo, manufactured by Aptuit, Verona, Italy) took the form of white, film-coated tablets with no markings provided in double-blinded treatment packs containing 2 doses. 
Ineligible patients had their end-of-study visit (visit 2) within 7 days of phone contact to return the study drug.

Eligible patients entered an outpatient treatment period in which they were asked to treat their next migraine attack within 4 hours of onset, provided that the headache severity was either moderate or severe and not improving. Patients recorded their response to the first dose over the next 48 hours using an electronic diary.

Patients were asked not to use rescue medication until at least 2 hours after dosing with the study drug; if the migraine did not respond at 2 hours, the second dose of study drug could be taken up to 24 hours after the first dose provided that no other rescue medication had been used. If the migraine responded within 2 hours (i.e., the headache became pain free) but then recurred after 2 hours, the second dose of study drug could be taken up to 24 hours after the first dose. The electronic diary was restarted if a patient took a second dose.

Patients who entered the treatment period had their end-ofstudy visit (visit 2) within 7 days of the treated attack or after 8 weeks if no attack was treated.

\section{Outcome measures}

At the time of migraine attack, before dosing, patients used the electronic diary to record the date and time of migraine onset and the level of headache pain and indicated the presence or absence of associated symptoms of migraine (nausea, phonophobia, and photophobia). Headache pain was rated by patients using the International Headache Society 4-point headache severity rating scale: none (0), mild (1), moderate (2), or severe (3). ${ }^{19}$ From the list of associated symptoms, patients selected the one they considered to be the MBS. Patients also recorded the date and time of taking the first dose of study drug. Baseline was defined as the last available measurement before the first dose.

With regard to efficacy, the electronic diary collected the following data at baseline and at $0.5,1,1.5,2,3,4,24$, and 48 hours after dose: the current level of headache pain, the presence or absence of associated symptoms of migraine (nausea, phonophobia, photophobia), the presence or absence of vomiting, and the level of disability. Patient-reported level of disability (degree of interference with normal activities) was rated with a 4-point scale: not at all (0); mild interference (1); marked interference (2); and completely, needs bed rest (3). In addition, at 2 hours after dose, patients recorded their global impression of change using a 7-point scale: very much better, much better, a little better, no change, a little worse, much worse, or very much worse.

With regard to safety and tolerability, the electronic diary asked patients if they felt "anything unusual" since taking the study medication that they had not felt with a migraine before; if yes, they received a follow-up phone call from the site. At the end-of-study visit, safety was assessed by adverse events, clinical laboratory parameters, physical examination, vital signs, ECGs, and the Columbia Suicide Severity Rating
Scale. $^{20}$ A treatment-emergent adverse event (TEAE) was defined as an event that started or worsened after the first dose of study medication (i.e., it did not present with the migraine) and occurred within 48 hours of the last dose.

The electronic diary also documented the use of rescue/ recurrence medication and any other concomitant medication that had not been recorded at the screening visit.

\section{Data analysis}

The sample size was determined on the basis of the proportion of patients who were headache pain free at 2 hours in a phase $2 \mathrm{~B}$ study ( $18.8 \%$ for lasmiditan $200 \mathrm{mg}, 13.6 \%$ for lasmiditan $100 \mathrm{mg}$, and $7.4 \%$ for placebo). ${ }^{14}$ With a 1-sided, 2-sample comparison at the $2.5 \%$ level of significance, a sample size of 570 patients per treatment group (as defined by the first dose) provided $>90 \%$ power to detect a difference in the proportion of patients who were headache pain free at 2 hours for lasmiditan $200 \mathrm{mg}$ and lasmiditan $100 \mathrm{mg}$.

The safety population was defined as all randomized patients who used at least 1 dose of study drug, regardless of whether they underwent any study assessments. The intent-to-treat (ITT) population was defined as all patients in the safety population who recorded any postdose headache severity or symptom assessments in the electronic diary, and the mITT population was defined as all patients in the ITT population who treated a migraine attack within 4 hours of onset.

The primary efficacy endpoint was a comparison between lasmiditan $200 \mathrm{mg}$ and placebo of the proportion of patients who were headache pain free at 2 hours after the first dose of study medication (in the mITT population). Endpoints were analyzed in a sequential gatekeeping procedure to prevent Type I error inflation. As such, the $100 \mathrm{mg}$ endpoints were considered secondary to $200 \mathrm{mg}$ endpoints. Headache pain free was defined as a reduction in headache severity from mild (1), moderate (2), or severe (3) at baseline to none (0). If a second dose was taken within 2 hours, the patient was considered to be a nonresponder to the first dose.

The key secondary efficacy endpoints were (1) a comparison between lasmiditan $200 \mathrm{mg}$ and placebo of the proportion of patients who were MBS free at 2 hours after the first dose of study medication (MBS free was defined as a change from "yes" to "no" for the presence of the patient's baseline MBS [nausea, phonophobia, or photophobia]); (2) a comparison between lasmiditan $100 \mathrm{mg}$ and placebo of the proportion of patients who were headache pain free at 2 hours after the first dose; and (3) a comparison between lasmiditan $100 \mathrm{mg}$ and placebo of the proportion of patients who were MBS free at 2 hours after the first dose (all in the mITT population). For the primary and key secondary efficacy analyses, patients with missing data were assumed to be nonresponders.

Other secondary efficacy endpoints included comparisons between lasmiditan $200 \mathrm{mg} / 100 \mathrm{mg}$ and placebo of the proportion 
of patients who were headache pain free and MBS free at other time points (in the mITT population); the proportion of patients with sustained pain freedom (defined as being headache pain free at 2 hours after the first dose and at the indicated assessment time, having not used any medications after the first dose) (mITT population); the proportion of patients with headache pain relief (defined as a reduction in headache severity from moderate [2] or severe [3] at baseline to mild [1] or none $[0]$ or a reduction in headache severity from mild [1] at baseline, to none [0]); the proportion of patients who were free of migraine symptoms (vomiting, nausea, phonophobia, and photophobia); patient global impression of change; level of disability; and the proportion of patients who used a second dose of study drug for rescue or recurrence (all in the ITT population).

All primary and secondary efficacy analyses were made with a logistic regression model (Wald $\chi^{2}$ test), with treatment group and background use of migraine preventive medication as covariates. For treatment comparisons, an estimate of the odds ratio of achieving a response, as well as the corresponding confidence interval and $p$ value with the Wald test, was computed. Exceptions to this were global impression of change and level of disability, which used a Cochran-Mantel-Haenszel test controlling for background use of migraine preventive medication. The primary and key secondary endpoints were tested at a 1-sided significance level of 0.025 . A testing hierarchy was used to prevent type I error inflation for multiple comparisons: the primary efficacy endpoint was tested first, and if it was statistically significant, the key secondary efficacy endpoints were tested sequentially. Continuous variables were summarized with descriptive statistics; categorical variables were summarized with counts and percentages. Other secondary efficacy endpoints were tested at a 2 -sided significance level of 0.05 .

\section{Data availability}

The study was registered at ClinicalTrials.gov, and the data are available here (identifier NCT02439320).

\section{Results}

\section{Patients}

A total of 2,231 patients were randomized, of whom 1,856 (83.2\%) used the first dose of study drug and were included in the safety population (figure 1 ). Of these 1,856 treated patients, 1,805

Figure 1 Study flow (first dose)

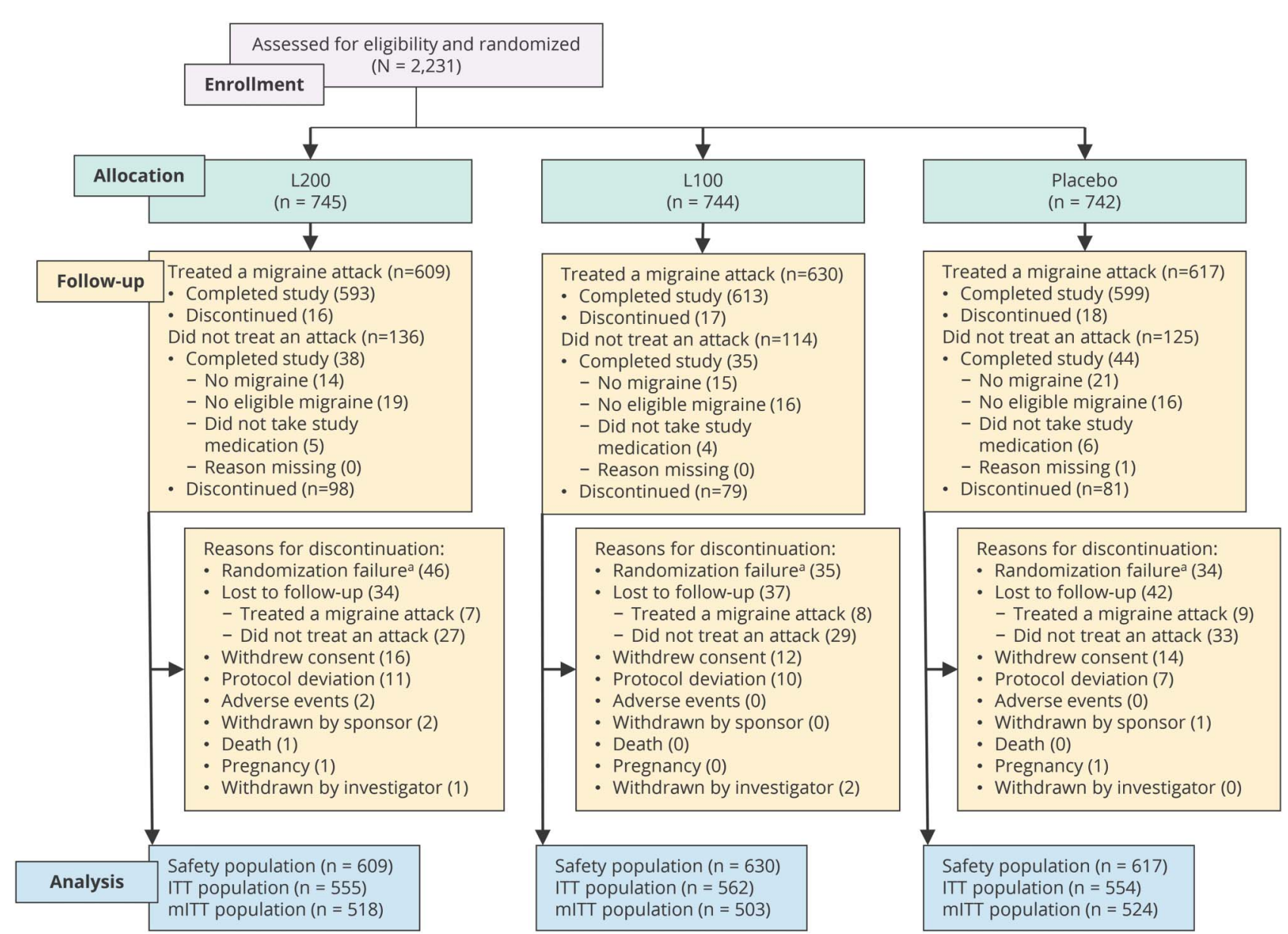

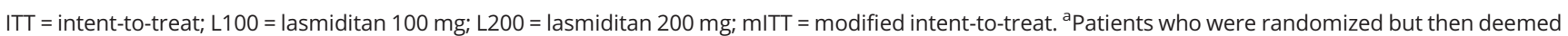
ineligible at the telephone confirmation (after completion of all screening evaluations). 
Table 1 Baseline demographic and clinical characteristics and characteristics of treated migraines

\begin{tabular}{|c|c|c|c|}
\hline Safety population & $\begin{array}{l}\text { Lasmiditan } \\
200 \mathrm{mg}(n=609)\end{array}$ & $\begin{array}{l}\text { Lasmiditan } \\
100 \mathrm{mg}(\mathrm{n}=630)\end{array}$ & $\begin{array}{l}\text { Placebo } \\
(n=617)\end{array}$ \\
\hline \multicolumn{4}{|c|}{ Demographic characteristics } \\
\hline Age, mean (SD), y & $41.4(12.0)$ & $42.2(11.7)$ & $42.4(12.3)$ \\
\hline Female, n (\%) & $515(84.6)$ & $512(81.3)$ & $525(85.1)$ \\
\hline White, n (\%) & $450(73.9)$ & $471(74.8)$ & $479(77.6)$ \\
\hline BMI, mean (SD), kg/m² & $31.0(8.2)(n=608)$ & $30.0(8.0)(n=629)$ & $30.3(7.5)(n=615)$ \\
\hline \multicolumn{4}{|c|}{ Clinical characteristics } \\
\hline MIDAS total score, mean (SD) & $32.0(21.7)$ & $30.4(21.2)$ & $32.2(23.7)$ \\
\hline Duration of migraine history, mean (SD), y & $18.9(13.1)$ & $19.7(13.0)$ & $19.3(12.7)$ \\
\hline Migraines per month in the past 3 mo, mean (SD), $n$ & $5.3(2.3)$ & $5.1(1.8)$ & $5.1(1.8)$ \\
\hline History of aura, $\mathbf{n}(\%)$ & $195(32.0)$ & $205(32.5)$ & $194(31.4)$ \\
\hline Background use of migraine preventive medication, $n(\%)$ & $111(18.2)$ & $97(15.4)$ & $103(16.7)$ \\
\hline$\geq 1$ Cardiovascular risk factors, $n(\%)^{a}$ & $471(77.3)$ & $489(77.6)$ & $485(78.6)$ \\
\hline$\geq 2$ Cardiovascular risk factors, $n(\%)^{a}$ & $248(40.7)$ & $254(40.3)$ & $257(41.7)$ \\
\hline mITT population, $n$ & 518 & 503 & 524 \\
\hline
\end{tabular}

\begin{tabular}{|c|c|c|c|}
\hline \multicolumn{4}{|c|}{ Characteristics of treated migraine } \\
\hline Severe headache (3), n (\%) & $148(28.6)$ & $132(26.2)$ & $145(27.7$ \\
\hline Moderate headache (2), n (\%) & $355(68.5)$ & $366(72.8)$ & $370(70.6$ \\
\hline Mild headache (1), $n(\%)^{b}$ & $15(2.9)$ & $5(1.0)$ & $9(1.7)$ \\
\hline Time to dosing from migraine start, mean (SD), $h$ & $1.1(1.9)$ & $1.0(2.3)$ & $1.0(2.2)$ \\
\hline
\end{tabular}

\begin{tabular}{|c|c|c|c|}
\hline \multicolumn{4}{|c|}{ Symptoms associated with treated migraine, $n(\%)$} \\
\hline Nausea & $232(44.8)$ & $210(41.7)$ & $221(42.2)$ \\
\hline Phonophobia & $322(62.2)$ & $303(60.2)$ & $327(62.4)$ \\
\hline Photophobia & $391(75.5)$ & $386(76.7)$ & $416(79.4)$ \\
\hline None & $37(7.1)$ & $34(6.8)$ & $36(6.9)$ \\
\hline MBS, n (\%) & $(n=481)$ & $(n=469)$ & $(n=488)$ \\
\hline Nausea & $118(24.5)$ & $115(24.5)$ & $115(23.6)$ \\
\hline Phonophobia & $96(20.0)$ & $117(24.9)$ & $104(21.3)$ \\
\hline Photophobia & $267(55.5)$ & $237(50.5)$ & 269 (55.1) \\
\hline
\end{tabular}

\begin{tabular}{lccc}
\hline & Probability of selecting symptom as MBS among those who had the symptom, $\mathrm{n} / \mathrm{N}(\%)^{\mathbf{c}}$ & \\
\hline Nausea & $118 / 232(50.9)$ & $115 / 210(54.8)$ & $115 / 221(52.0)$ \\
\hline Phonophobia & $96 / 322(29.8)$ & $117 / 303(38.6)$ & $104 / 327(31.8)$ \\
\hline Photophobia & $267 / 391(68.3)$ & $237 / 386(61.4)$ & $269 / 416(64.7)$ \\
\hline
\end{tabular}

Abbreviations: $\mathrm{BMI}=$ body mass index; $\mathrm{MBS}=$ most bothersome symptom; MIDAS = Migraine Disability Assessment; mITT = modified intent-totreat.

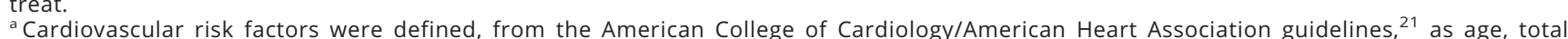
and high-density lipoprotein cholesterol, systolic blood pressure (including treated or untreated status), diabetes mellitus, and current smoking status.

b Patients were encouraged not to take their dose until the migraine was either moderate or severe as per the study protocol; however, following US Food and Drug Administration advice, mild headache was included as an option to choose in the electronic diary. These patients are shown here although they deviated from the protocol.

c Defined as the number of patients who selected the symptom as the MBS (n) relative to the number of patients with the particular symptom at baseline $(\mathrm{N})$. 
Table 2 Efficacy outcomes by treatment group

\begin{tabular}{|c|c|c|c|}
\hline mITT population & Lasmiditan $200 \mathrm{mg}$ & Lasmiditan $100 \mathrm{mg}$ & Placebo \\
\hline Headache pain free, $n^{a}$ & 518 & 503 & 524 \\
\hline At $2 \mathrm{~h}, \mathrm{n}(\%)$ & $167(32.2)$ & $142(28.2)$ & $80(15.3)$ \\
\hline Odds ratio $(95 \% \mathrm{Cl})$ & $2.6(2.0-3.6)$ & $2.2(1.6-3.0)$ & \\
\hline$p$ Value vs placebo & $<0.001$ & $<0.001$ & \\
\hline MBS free, $n^{b}$ & 481 & 469 & 488 \\
\hline At $2 \mathrm{~h}, \mathrm{n}(\%)$ & $196(40.7)$ & $192(40.9)$ & $144(29.5)$ \\
\hline Odds ratio $(95 \% \mathrm{Cl})$ & $1.6(1.3-2.1)$ & $1.7(1.3-2.2)$ & \\
\hline$p$ Value vs placebo & $<0.001$ & $<0.001$ & \\
\hline Sustained pain freedom (ITT population), $\mathrm{n}^{\mathrm{c}}$ & 555 & 562 & 554 \\
\hline At $24 \mathrm{~h}, \mathrm{n}(\%)$ & $103(18.6)$ & $83(14.8)$ & $42(7.6)$ \\
\hline Odds ratio $(95 \% \mathrm{Cl})^{\mathrm{d}}$ & $2.8(1.9-4.1)$ & $2.1(1.4-3.1)$ & \\
\hline$p$ Value vs placebo ${ }^{d}$ & $<0.001$ & $<0.001$ & \\
\hline At $48 \mathrm{~h}, \mathrm{n}(\%)$ & $91(16.4)$ & $84(14.9)$ & $42(7.6)$ \\
\hline Odds ratio $(95 \% \mathrm{Cl})^{d}$ & $2.4(1.6-3.5)$ & $2.1(1.5-3.2)$ & \\
\hline$p$ Value vs placebo ${ }^{d}$ & $<0.001$ & $<0.001$ & \\
\hline Other efficacy outcomes at $2 \mathrm{~h}$ (ITT population), $\mathrm{n}$ & 555 & 562 & 554 \\
\hline Headache relief, $n(\%)^{e}$ & $330(59.5)$ & $334(59.4)$ & $234(42.2)$ \\
\hline Odds ratio $(95 \% \mathrm{Cl})$ & $2.5(1.9-3.3)$ & $2.4(1.8-3.1)$ & \\
\hline$p$ Value vs placebo & $<0.001$ & $<0.001$ & \\
\hline Nausea free, n (\%) & $449(80.9)$ & $448(79.7)$ & $427(77.1)$ \\
\hline Odds ratio $(95 \% \mathrm{Cl})$ & $1.2(0.9-1.7)$ & $1.2(0.9-1.6)$ & \\
\hline$p$ Value vs placebo & 0.153 & 0.276 & \\
\hline Phonophobia free, $n$ (\%) & $419(75.5)$ & $426(75.8)$ & $374(67.5)$ \\
\hline Odds ratio $(95 \% \mathrm{Cl})$ & $1.5(1.1-1.9)$ & $1.6(1.2-2.0)$ & \\
\hline$p$ Value vs placebo & 0.005 & 0.002 & \\
\hline Photophobia free, n (\%) & $379(68.3)$ & $388(69.0)$ & $294(53.1)$ \\
\hline Odds ratio $(95 \% \mathrm{Cl})$ & $2.0(1.5-2.6)$ & $2.1(1.7-2.8)$ & \\
\hline$p$ Value vs placebo & $<0.001$ & $<0.001$ & \\
\hline Vomiting free, $n(\%)$ & $546(98.4)$ & $549(97.7)$ & $546(98.6)$ \\
\hline Odds ratio $(95 \% \mathrm{Cl})$ & $0.9(0.3-2.3)$ & $0.6(0.3-1.5)$ & \\
\hline$p$ Value vs placebo & 0.773 & 0.286 & \\
\hline
\end{tabular}

Abbreviations: $\mathrm{Cl}$ = confidence interval; ITT = intent-to-treat; $\mathrm{MBS}=$ most bothersome symptom; $\mathrm{mITT}=$ modified intent-to-treat.

a Defined as a reduction in headache severity from mild (1), moderate (2), or severe (3) at baseline to none (0).

b Defined as the absence of the associated symptom of migraine that was identified before dose as the MBS (nausea, phonophobia, or photophobia).

${ }^{\mathrm{C}}$ Defined as being headache pain free at 2 hours after the first dose and at the indicated assessment time, having not used any medications after the first dose.

${ }^{\mathrm{d}}$ A post hoc analysis.

e Defined as a reduction in headache severity from moderate (2) or severe (3) at baseline to mild (1) or none (0) or a reduction in headache severity from mild

(1) at baseline to none (0).

(97.3\%) completed the study, and 51 (2.7\%) discontinued. Of the 375 patients who did not treat a migraine attack, 117 completed the study (generally having experienced no migraine or no eligible migraine), and 258 discontinued. Two patients discontinued the study due to an adverse event without having taken study drug, and thus were not part of the safety population or the 
ITT/mITT populations. Discontinuation rates were similar between treatment groups. The most common reasons for discontinuation were randomization failure (patients who were randomized but then deemed ineligible at the telephone confirmation), patient lost to follow-up, patient withdrew consent, and noncompliance with the protocol (figure 1).

Patient baseline demographic and clinical characteristics were similar between treatment groups (table 1). The majority of patients in the safety population were female $(83.6 \%)$ and white $(75.4 \%)$, and the mean age was 42.0 (SD 12.0) years. Overall, 1,445 patients $(77.9 \%)$ had at least 1 cardiovascular risk factor in addition to migraine (table 1). A full list of cardiovascular risk factors is presented in table e- 1 available from Dryad (doi.org/10.5061/dryad.s3p3m0d).

At baseline, patients had suffered from migraines for a mean duration of 19.3 (SD 12.9) years and had experienced a mean of 5.1 (SD 1.9) migraines per month in the past 3 months, and $32.0 \%$ had experienced migraine with aura. MIDAS total scores and history of headaches at baseline were generally similar across the treatment groups. Overall, the mean MIDAS total score was 31.5 (SD 22.2); patients had a mean of 17.4 (SD 10.6) days with headache in the past 3 months, with mean headache pain (scored from 0 [no pain at all] to 10 [pain as bad as it could be]) of 7.5 (SD 1.6).

Characteristics of treated migraines were similar between treatment groups (table 1). Photophobia was the most commonly reported symptom associated with the treated migraine and the most commonly reported $\mathrm{MBS}$ in each treatment group. Overall, among patients who reported an MBS, $53.8 \%$ selected photophobia, $24.2 \%$ selected nausea, and $22.0 \%$ selected phonophobia.

\section{Efficacy}

Statistically significantly more patients dosed with lasmiditan $200 \mathrm{mg}$ (32.2\%, $p<0.001$, primary efficacy analysis) and lasmiditan $100 \mathrm{mg}(28.2 \%, p<0.001)$ were free of headache pain at 2 hours after the first dose compared with patients who received placebo (15.3\%) (table 2). Superiority over placebo $(p<0.05)$ was noted after 1 hour in the lasmiditan $200 \mathrm{mg}$ group and after 1.5 hours in the lasmiditan $100 \mathrm{mg}$ group (figure $2 \mathrm{~A}$ ).

Similarly, statistically significantly more patients dosed with lasmiditan $200 \mathrm{mg}$ (40.7\%, $p<0.001$, key secondary efficacy analysis) and lasmiditan $100 \mathrm{mg}(40.9 \%, p<0.001)$ were free of their MBS at 2 hours after the first dose compared with patients who received placebo (29.5\%) (table 2). The proportion of MBS-free patients was greater than placebo $(p<$ 0.05 ) from 0.5 hours on in both lasmiditan groups (figure $2 \mathrm{~B}$ ).

Considering the other secondary efficacy analyses, a greater proportion of patients in the lasmiditan $200 \mathrm{mg}$ and lasmiditan $100 \mathrm{mg}$ groups had headache relief at 2 hours than in the placebo group (table 2 and figure 2C). Lasmiditan also showed benefits over placebo $(p<0.05)$ at 2 hours in terms of the proportion of patients free of the migraine symptoms of
Figure 2 Headache pain free, MBS free, and headache relief after the first dose

A. Headache, pain-free ${ }^{a}$ (mITT population)

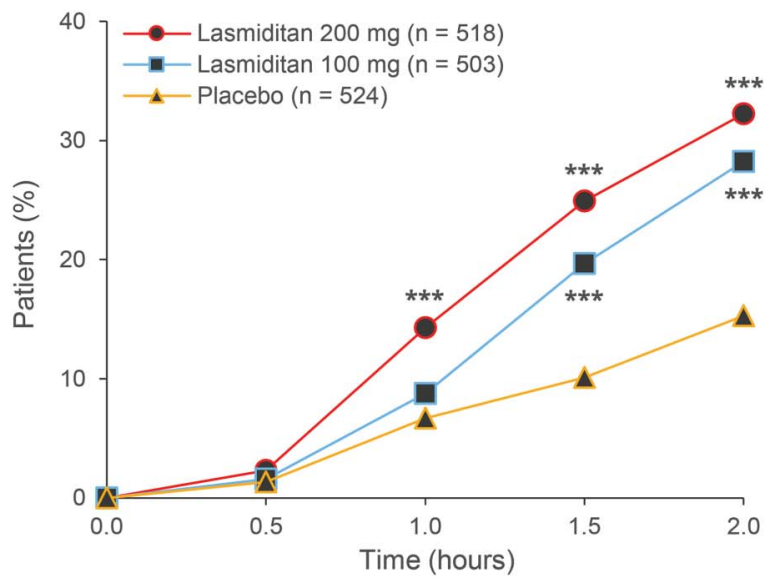

B. MBS-free ${ }^{b}$ (mITT population)

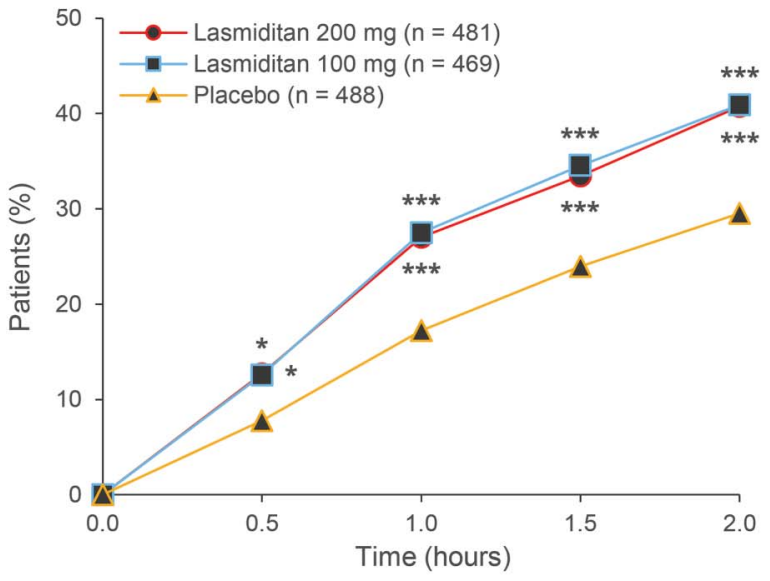

C. Headache relief` (ITT population)

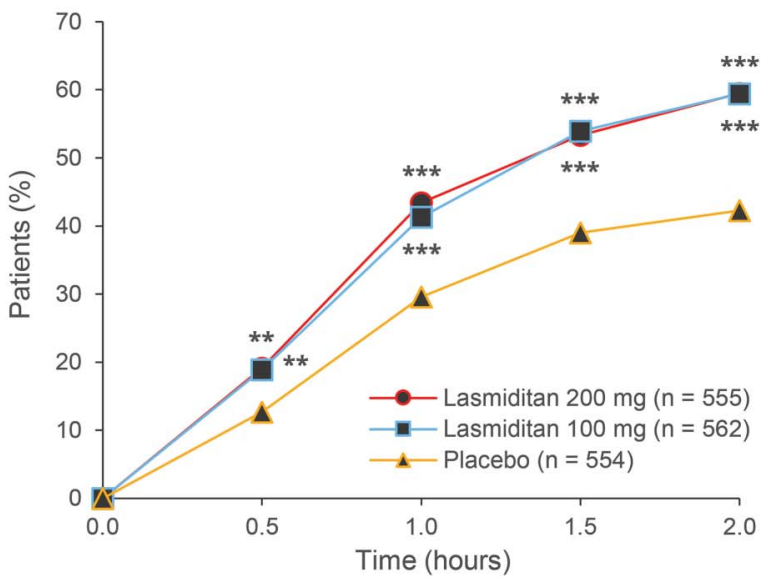

${ }^{a}$ Defined as a reduction in (A) headache severity from mild (1), moderate (2), or severe (3) at baseline to none (0). ${ }^{b}$ Defined as (B) the absence of the associated symptom of migraine that was identified before dose as the most bothersome symptom (MBS) (nausea, phonophobia, or photophobia). ${ }^{\mathrm{C}}$ Defined as (C) a reduction in headache severity from moderate (2) or severe (3) at baseline to mild (1) or none (0) or a reduction in headache severity from mild (1) at baseline to none (0). ${ }^{*} p<0.05,{ }^{* *} p<0.01,{ }^{* * *} p \leq 0.001$ vs placebo. ITT = intent-to-treat; mITT = modified intent-to-treat. 
Table 3 Patient global impression of change and disability level by treatment group

\begin{tabular}{|c|c|c|c|}
\hline ITT population & $\begin{array}{l}\text { Lasmiditan } \\
200 \mathrm{mg}(\mathrm{n}=555)\end{array}$ & $\begin{array}{l}\text { Lasmiditan } \\
100 \mathrm{mg}(\mathrm{n}=562)\end{array}$ & $\begin{array}{l}\text { Placebo } \\
(n=554)\end{array}$ \\
\hline \multicolumn{4}{|c|}{ Global impression of change at $2 \mathrm{~h}, \mathrm{n}(\%)$} \\
\hline Very much better & $57(10.3)$ & $54(9.6)$ & $34(6.1)$ \\
\hline Much better & $153(27.6)$ & $155(27.6)$ & $87(15.7)$ \\
\hline A little better & $143(25.8)$ & $153(27.2)$ & $159(28.7)$ \\
\hline No change & $60(10.8)$ & $83(14.8)$ & $146(26.4)$ \\
\hline A little worse & $31(5.6)$ & $16(2.8)$ & $28(5.1)$ \\
\hline Much worse & $13(2.3)$ & $8(1.4)$ & $14(2.5)$ \\
\hline Very much worse & $5(0.9)$ & $8(1.4)$ & $3(0.5)$ \\
\hline$p$ Value vs placebo & $<0.001$ & $<0.001$ & \\
\hline \multicolumn{4}{|c|}{ Disability level at 2 h, n (\%) } \\
\hline Not at all (0) & $180(32.4)$ & $181(32.2)$ & $119(21.5)$ \\
\hline Mild interference (1) & $115(20.7)$ & $137(24.4)$ & $156(28.2)$ \\
\hline Marked interference (2) & $92(16.6)$ & $95(16.9)$ & $122(22.0)$ \\
\hline Completely, needs bed rest ( 3 ) & $75(13.5)$ & $64(11.4)$ & 74 (13.4) \\
\hline$p$ Value vs placebo & $<0.001$ & $<0.001$ & \\
\hline
\end{tabular}

Abbreviation: ITT = intent-to-treat.

phonophobia or photophobia (table 2) and in global impression of change and disability level ratings (table 3 ).

Patients who received lasmiditan as a first dose were less likely to use a second dose of study drug than patients who received placebo as a first dose: $31.9 \%$ (177 of 555) of the lasmiditan $200 \mathrm{mg}$ group, $39.0 \%$ (219 of 562) of the lasmiditan $100 \mathrm{mg}$ group, and $59.9 \%$ (332 of 554) of the placebo group took a second dose between 2 and 24 hours after the first dose for rescue or recurrence (ITT population). Of these second doses, 676 were taken as rescue medication and 52 as recurrence medication.

\section{Tolerability and safety}

A total of 260 patients (42.7\%) in the lasmiditan $200 \mathrm{mg}$ group and 229 patients (36.3\%) in the lasmiditan $100 \mathrm{mg}$ group experienced at least 1 TEAE after the first dose compared with 101 patients (16.4\%) in the placebo group (table 4). The majority of TEAEs were mild or moderate in intensity. TEAEs that occurred with an incidence of $\geq 2 \%$ in any lasmiditan group and greater than placebo were dizziness, fatigue, lethargy, nausea, paresthesia, and somnolence (table 4). No serious TEAEs related to study drug were reported, and no adverse events resulted in study discontinuation among those patients who used study drug. No patients showed suicidality, and there were no deaths during the treatment period. One patient died of an accidental overdose of methadone and oxycodone before taking the study drug.
The incidence of cardiovascular TEAEs was low (table 4). After the first dose, the only cardiovascular TEAEs considered reasonably or possibly related to study drug were palpitations in 3 patients $(0.5 \%)$ receiving lasmiditan $200 \mathrm{mg}$ and 2 patients (0.3\%) receiving lasmiditan $100 \mathrm{mg}$ and bradycardia for $1 \mathrm{pa}-$ tient $(0.2 \%)$ receiving lasmiditan $100 \mathrm{mg}$. A post hoc analysis of the incidence of TEAEs in patients with $\geq 2$ cardiovascular risk factors at baseline is shown in table e-2 (available from Dryad, doi.org/10.5061/dryad.s3p3m0d); a similar pattern of TEAEs was observed in the full population.

There were no clinically meaningful differences in hematology, blood chemistry, urinalysis, vital signs, physical examination, or ECGs across treatment groups or with regard to changes from baseline.

\section{Discussion}

In this first phase 3, randomized, double-blind, placebocontrolled study of lasmiditan for the acute treatment of migraines, statistically significantly more patients who took lasmiditan (200 and $100 \mathrm{mg}$ ) experienced freedom from headache pain and MBS at 2 hours than patients who took placebo. These primary/key secondary outcomes were approved by the US FDA in a Special Protocol Assessment before the release of its draft guidance for studies of the acute treatment of migraines. ${ }^{22}$ Previously, migraine drugs needed to demonstrate statistically significant benefits for pain and all 
Table 4 Treatment-emergent adverse events (TEAEs) after the first dose

\begin{tabular}{|c|c|c|c|}
\hline Safety population & $\begin{array}{l}\text { Lasmiditan } 200 \mathrm{mg} \\
(\mathrm{n}=609), \mathrm{n}(\%)\end{array}$ & $\begin{array}{l}\text { Lasmiditan } 100 \mathrm{mg} \\
(\mathrm{n}=630), \mathrm{n}(\%)\end{array}$ & $\begin{array}{l}\text { Placebo } \\
(n=617), n(\%)\end{array}$ \\
\hline At least 1 TEAE & $260(42.7)$ & $229(36.3)$ & $101(16.4)$ \\
\hline At least 1 TEAE related to study medication & 237 (38.9) & $205(32.5)$ & $78(12.6)$ \\
\hline At least 1 serious TEAE & $2(0.3)$ & $0(0.0)$ & $1(0.2)$ \\
\hline \multicolumn{4}{|c|}{ TEAEs with incidence $\geq 2 \%$ in any lasmiditan group and greater than placebo } \\
\hline Dizziness & $99(16.3)$ & $79(12.5)$ & $21(3.4)$ \\
\hline Paresthesia & $48(7.9)$ & $36(5.7)$ & $13(2.1)$ \\
\hline Somnolence & $33(5.4)$ & $36(5.7)$ & $14(2.3)$ \\
\hline Nausea & $32(5.3)$ & $19(3.0)$ & $12(1.9)$ \\
\hline Fatigue & $19(3.1)$ & $26(4.1)$ & $2(0.3)$ \\
\hline Lethargy & $15(2.5)$ & $12(1.9)$ & $2(0.3)$ \\
\hline \multicolumn{4}{|c|}{ Incidence of cardiovascular TEAEs } \\
\hline Palpitations & $4(0.7)$ & $2(0.3)$ & $0(0.0)$ \\
\hline Sinus bradycardia & $1(0.2)$ & $0(0.0)$ & $0(0.0)$ \\
\hline Bradycardia & $0(0.0)$ & $1(0.2)$ & $1(0.2)$ \\
\hline Tachycardia & $0(0.0)$ & $1(0.2)$ & $0(0.0)$ \\
\hline Left ventricular hypertrophy & $0(0.0)$ & $0(0.0)$ & $1(0.2)$ \\
\hline
\end{tabular}

Abbreviation: TEAE = treatment-emergent adverse event (an event that started or worsened after the first dose of study medication [i.e., it did not present with the migraine] and occurred within 48 hours of dosing).

3 associated symptoms (nausea, phonophobia and photophobia) to be granted approval by the FDA, ${ }^{22}$ despite a high proportion of patients not having nausea at baseline. The present study reports MBS as a major endpoint, an approach that reduces multiple comparisons and may improve statistical power to detect treatment effects. Individual associated symptoms were assessed as secondary endpoints and showed benefits for lasmiditan on phonophobia and photophobia but not nausea. Photophobia was the most commonly reported MBS at baseline, reported by more than half of patients, whereas nausea was the MBS for only around a quarter of patients. The use of patient-centric endpoints such as the MBS in clinical trials is important to allow meaningful benefits to the patient to be measured.

The outcomes were measured with real-time data captured by electronic diaries. The diaries did not allow retrospective data entry (each time point became available on the basis of the patient-recorded time of dosing and was available for \pm 5 minutes), offering an advantage over paper diaries. Of note, the placebo response rate for freedom from headache pain at 2 hours after dosing was higher in this study (15.3\%) than in studies of oral triptans (generally $<10 \%){ }^{23}$ which may be partly attributed to increased patient contact by the site (investigators were asked to call patients who did not feel well, who reported unusual symptoms, and who were not compliant).
Secondary analyses were supportive of the efficacy of lasmiditan. Rates of sustained pain freedom at 24 and 48 hours showed benefits for lasmiditan over placebo, but differences were smaller than expected, perhaps because of poor diary adherence at 24 hours. Patients who received lasmiditan as a first dose were less likely to take a second dose of study drug for rescue or recurrence than patients who received placebo as a first dose (31.9\% of the lasmiditan $200 \mathrm{mg}$ group, $39.0 \%$ of the lasmiditan $100 \mathrm{mg}$ group, and $59.9 \%$ of the placebo group compared with $20 \%-34 \%$ in studies of oral triptans ${ }^{24}$ ).

Treatment with lasmiditan was generally well tolerated and safe. Adverse events were captured with the real-time electronic diaries: if the patients felt anything unusual since taking the study medication that they had not felt with a migraine before, this was recorded, and they were contacted by an investigator within 24 hours for further discussion. Adverse events were also discussed at the end-of-study visit. The incidence of TEAEs was higher in the lasmiditan 200 and $100 \mathrm{mg}$ groups compared with the placebo group; however, the majority of TEAEs were mild or moderate in intensity. Activity limitations did not differ within treatment groups among those with treatment-emergent dizziness and those who did not have treatment-emergent dizziness. These data will be reported in detail separately. There were no deaths during the treatment period; no serious TEAEs related to 
study drug were reported; and no TEAEs resulted in discontinuation of the study among those patients who had used study drug. Most TEAEs were nervous system related, and the incidence of cardiovascular TEAEs with lasmiditan was low. Overall, the safety profile of lasmiditan was consistent with the phase 2 studies. ${ }^{14,25}$

Patients with cardiovascular risk factors and many stable forms of cardiovascular disease were eligible to participate in this clinical study, and the majority of patients (77.9\%) had at least 1 cardiovascular risk factor at baseline. While no clinical trial is fully generalizable to clinical practice, the inclusion of patients with cardiovascular risk factors increases the generalizability of this study to real-world populations.

Lasmiditan dosed at 200 and at $100 \mathrm{mg}$ was efficacious and well tolerated in the treatment of acute migraine among patients with a high level of cardiovascular risk factors.

\section{Author contributions}

B. Kuca: conceptualization of study, author of study protocol, overall study director, reviewing of manuscript. S.D. Silberstein: study investigator, reviewing of manuscript. L. Wietecha: revising the manuscript for intellectual content. P.H. Berg: analysis and interpretation of the data, statistical analysis, revising the manuscript for intellectual content. G. Dozier: author of analysis plan, advising and reviewing of analysis programming, statistical analysis, reviewing of manuscript. R.B. Lipton: conceptualization of study, study investigator, reviewing of manuscript.

\section{Acknowledgment}

Writing support was provided by Chris Watling, $\mathrm{PhD}$, assisted by his colleagues at Cambridge Medical Communication Ltd (Cambridge, UK), and funded by CoLucid Pharmaceuticals, Inc, a wholly owned subsidiary of Eli Lilly and Company.

\section{Study funding}

Funded by CoLucid Pharmaceuticals, Inc, a wholly owned subsidiary of Eli Lilly and Company.

\section{Disclosure}

B. Kuca: at the time that this work was conducted, employed as senior management of CoLucid and had CoLucid stock. S. Silberstein: as a consultant and/or advisory panel member, Dr. Stephen D. Silberstein receives or has received honoraria from Alder Biopharmaceuticals; Allergan, Inc; Amgen; Avanir Pharmaceuticals, Inc; Curelator, Inc; Dr. Reddy's Laboratories; eNeura Inc; electroCore Medical, LLC; Lilly USA, LLC; Medscape, LLC; National Institute of Neurological Disorders and Stroke; Supernus Pharmaceuticals, Inc; Teva Pharmaceuticals; Theranica; and Trigemina, Inc. L. Wietecha and P. Berg: employed by and stockholder of Eli Lilly and Company. G. Dozier: former employee of IQVIA, which was under contract (under the previous name of Quintiles) with CoLucid to manage and analyze the study. R. Lipton: Dr.
Richard B. Lipton is the Edwin S. Lowe Professor of Neurology at the Albert Einstein College of Medicine in New York. He receives research support from the NIH: 2PO1 AG003949 (program director), 5U10 NS077308 (primary investigator), 1RO1 AG042595 (investigator), RO1 NS082432 (investigator), K23 NS09610 (mentor), and K23AG049466 (mentor). He also receives support from the Migraine Research Foundation and the National Headache Foundation. He serves on the Editorial Boards of Neurology and Cephalalgia and as senior advisor to Headache. He has reviewed for the National Institute on Aging and National Institute on Neurological Disorders and Stroke; holds stock options in eNeura Therapeutics and Biohaven Holdings; and serves as consultant or advisory board member or has received honoraria from the American Academy of Neurology, Alder, Allergan, American Headache Society, Amgen, Autonomic Technologies, Avanir, Biohaven, Biovision, Boston Scientific, Dr. Reddy's, Electrocore, Eli Lilly, eNeura Therapeutics, GlaxoSmithKline, Merck, Pernix, Pfizer, Supernus, Teva, Trigemina, Vector, and Vedanta. He receives royalties from Wolff's Headache, 8th Edition, Oxford Press University, 2009, Wiley, and Informa. Go to Neurology. org/ $\mathrm{N}$ for full disclosures.

\section{Publication history}

Received by Neurology February 28, 2018. Accepted in final form September 17, 2018.

\section{References}

1. GBD 2016 Disease and Injury Incidence and Prevalence Collaborators. Global, regional, and national incidence, prevalence, and years lived with disability for 328 diseases and injuries for 195 countries, 1990-2016: a systematic analysis for the Global Burden of Disease Study 2016. Lancet 2017;390:1211-1259.

2. Cameron C, Shannon K, Hsieh S, et al. Triptans in the acute treatment of migraine: a systematic review and network meta-analysis. Headache 2015;55:221-235.

3. Napier C, Stewart M, Melrose H, Hopkins B, McHarg A, Wallis R. Characterisation of the 5-HT receptor binding profile of eletriptan and kinetics of $\left[{ }^{3} \mathrm{H}\right]$ eletriptan binding at human 5- $\mathrm{HT}_{1 \mathrm{~B}}$ and 5- $\mathrm{HT}_{1 \mathrm{D}}$ receptors. Eur J Pharmacol 1999;368:259-268.

4. Nilsson T, Longmore J, Shaw D, et al. Characterisation of 5-HT receptors in human coronary arteries by molecular and pharmacological techniques. Eur J Pharmacol 1999;372:49-56.

5. Humphrey PP, Feniuk W, Perren MJ, Beresford IJ, Skingle M, Whalley ET. Serotonin and migraine. Ann NY Acad Sci 1990;600:587-598.

6. Dodick DW, Martin VT, Smith T, Silberstein S. Cardiovascular tolerability and safety of triptans: a review of clinical data. Headache 2004;44(suppl 1):S20-S30.

7. Gilmore B, Michael M. Treatment of acute migraine headache. Am Fam Physician 2011;83:271-280.

8. Imitrex (sumatriptan succinate) tablets, for oral use [prescribing information]. Brentford, UK: GlaxoSmithKline; 2017.

9. Buse DC, Reed ML, Fanning KM, Kurth T, Lipton RB. Cardiovascular events, conditions, and procedures among people with episodic migraine in the US population: results from the American Migraine Prevalence and Prevention (AMPP) study. Headache 2017;57:31-44.

10. Lipton RB, Reed ML, Kurth T, Fanning KM, Buse DC. Framingham-based cardiovascular risk estimates among people with episodic migraine in the US population: results from the American Migraine Prevalence and Prevention (AMPP) study. Headache 2017;57:1507-1521.

11. Adelborg K, Szépligeti SK, Holland-Bill L, et al. Migraine and risk of cardiovascular diseases: Danish population based matched cohort study. BMJ 2018;360:k96.

12. Viana M, Genazzani AA, Terrazzino S, Nappi G, Goadsby PJ. Triptan nonresponders: do they exist and who are they? Cephalalgia 2013;33:891-896.

13. Nelson DL, Phebus LA, Johnson KW, et al. Preclinical pharmacological profile of the selective 5- $\mathrm{HT}_{1 \mathrm{~F}}$ receptor agonist lasmiditan. Cephalalgia 2010;30:1159-1169.

14. Färkkilä M, Diener HC, Géraud G, et al; COL MIG-202 Study Group. Efficacy and tolerability of lasmiditan, an oral 5- $\mathrm{HT}_{1 \mathrm{~F}}$ receptor agonist, for the acute treatment of migraine: a phase 2 randomised, placebo-controlled, parallel-group, dose-ranging study. Lancet Neurol 2012;11:405-413.

15. US Department of Health and Human Services, Food and Drug Administration. Special Protocol Assessment (SPA) guidance for industry: OMB control number 0910-0470. Available at: fda.gov/downloads/drugs/guidancecomplianceregulatoryinformation/guidances/ucm498793.pdf. Accessed November 6, 2018. 
16. Headache Classification Committee of the International Headache Society (IHS). The International Classification of Headache Disorders, 3rd edition (beta version). Cephalalgia 2013;33:629-808.

17. Stewart WF, Lipton RB, Whyte J, et al. An international study to assess reliability of the Migraine Disability Assessment (MIDAS) score. Neurology 1999;53: 988-994.

18. Stewart WF, Lipton RB, Kolodner K, Liberman J, Sawyer J. Reliability of the Migraine Disability Assessment score in a population-based sample of headache sufferers. Cephalalgia 1999;19:107-114.

19. Tfelt-Hansen P, Pascual J, Ramadan N, et al; International Headache Society Clinical Trials Subcommittee. Guidelines for controlled trials of drugs in migraine: third edition: a guide for investigators. Cephalalgia 2012;32:6-38.

20. Posner K, Brown GK, Stanley B, et al. The Columbia-Suicide Severity Rating Scale: initial validity and internal consistency findings from three multisite studies with adolescents and adults. Am J Psychiatry 2011;168:1266-1277.
21. Goff DC Jr, Lloyd-Jones DM, Bennett G, et al. 2013 ACC/AHA guideline on the assessment of cardiovascular risk: a report of the American College of Cardiology/ American Heart Association Task Force on Practice Guidelines. Circulation 2014; 129(suppl 2):S49-S73.

22. US Food and Drug Administration (FDA) Center for Drug Evaluation and Research (CDER). Migraine: Developing drugs for acute treatment. Guidance for industry. Available at https://www.fda.gov/downloads/Drugs/GuidanceComplianceRegulatoryInformation/ Guidances/UCM419465.pdf. Accessed November 7, 2018.

23. Ferrari MD, Roon KI, Lipton RB, Goadsby PJ. Oral triptans (serotonin $5-\mathrm{HT}_{1 \mathrm{~B} / 1 \mathrm{D}}$ agonists) in acute migraine treatment: a meta-analysis of 53 trials. Lancet 2001;358:1668-1675.

24. Cameron C, Kelly S, Hsieh SC, et al. Triptans in the acute treatment of migraine a systematic review and network meta-analysis. Headache 2015;55(suppl 4):221-235.

25. Ferrari MD, Färkkilä M, Reuter U, et al; European COL-144 Investigators. Acute treatment of migraine with the selective $5-\mathrm{HT}_{1 \mathrm{~F}}$ receptor agonist lasmiditan: a randomised proof-of-concept trial. Cephalalgia 2010;30:1170-1178. 


\section{Neurology}

Lasmiditan is an effective acute treatment for migraine: A phase 3 randomized study Bernice Kuca, Stephen D. Silberstein, Linda Wietecha, et al.

Neurology 2018;91;e2222-e2232 Published Online before print November 16, 2018

DOI 10.1212/WNL.0000000000006641

This information is current as of November 16, 2018

\section{Updated Information \& Services \\ References \\ Citations \\ Subspecialty Collections}

Permissions \& Licensing

Reprints including high resolution figures, can be found at: http://n.neurology.org/content/91/24/e2222.full

This article cites 22 articles, 3 of which you can access for free at: http://n.neurology.org/content/91/24/e2222.full\#ref-list-1

This article has been cited by 1 HighWire-hosted articles: http://n.neurology.org/content/91/24/e2222.full\#\#otherarticles

This article, along with others on similar topics, appears in the following collection(s):

\section{Class I}

http://n.neurology.org/cgi/collection/class_1

Clinical trials Randomized controlled (C)

http://n.neurology.org/cgi/collection/clinical_trials_randomized_contro

lled_consort_agreement

Migraine

http://n.neurology.org/cgi/collection/migraine

Patient safety

http://n.neurology.org/cgi/collection/patient_safety

Quality of life

http://n.neurology.org/cgi/collection/quality_of_life

Information about reproducing this article in parts (figures,tables) or in its entirety can be found online at:

http://www.neurology.org/about/about_the_journal\#permissions

Information about ordering reprints can be found online:

http://n.neurology.org/subscribers/advertise

Neurology $\mathbb{B}$ is the official journal of the American Academy of Neurology. Published continuously since 1951 , it is now a weekly with 48 issues per year. Copyright Copyright (C) 2018 The Author(s). Published by Wolters Kluwer Health, Inc. on behalf of the American Academy of Neurology.. All rights reserved. Print ISSN: 0028-3878. Online ISSN: 1526-632X.

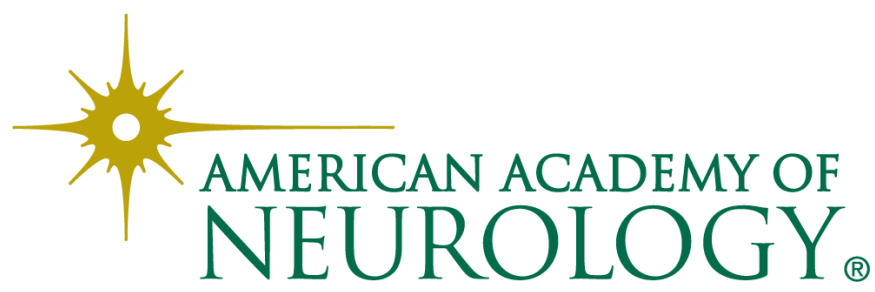

